\title{
Perception of the Farmers Regarding Constraints Faced during Farmers' Fair
}

\author{
Abdul Aziz Sattari ${ }^{1}$, Anil Kumar Malik ${ }^{1 *}$, Krishan Yadav ${ }^{1}$, Ramesh Kumar $^{2}$ and Dinesh Kumar ${ }^{3}$ \\ ${ }^{1}$ Department of Extension Education, CCS HAU, Hisar, Haryana, India \\ ${ }^{2}$ Krishi Vigyan Kendra, Ambala, Haryana, India \\ ${ }^{3}$ Department of Agricultural Economics, CCS HAU, Hisar, Haryana, India
}

*Corresponding author: malikanil100@gmail.com (ORCID ID: 0000-0002-7029-8792)

Received: 18-11-2020

Revised: $19-02-2021$

Accepted: 12-03-2021

\begin{abstract}
Famers' fair an important tool in transferring latest technologies to farmers is gaining momentum over the years. The main purpose of organizing such farmers' fair is to create awareness among visitors about new technologies developed by researchers primarily from the government sector, agricultural and allied research centres and State Agricultural Universities (SAUs). Considering its importance, an exploratory study was carried out to identify the constraints perceived by the visiting farmers and remedies suggested by them for improvement of farmers' fair. The present study was conducted at Chaudhary Charan Singh Haryana Agricultural University (CCS HAU), Hisar main campus during 2019-20. Empirical data were collected through personal interview technique with the help of well-structured and pre-tested interview schedule and analyzed using standard methodology. Findings revealed that infrastructural constraints were perceived highest with composite index value (CIV) of 38.28, followed by physical (34.37), institutional (30.00), miscellaneous (19.27) and social (07.81) constraints. With regards to suggestions, most of the farmers suggested time duration of farmers' fair should be increased followed by adequate transport facilities, seeds should be made available at low price, etc. Hence, the paper recommends that although the farmers' fairs are playing an effective role in information dissemination but must be updated each year to catch more attention of the farmers.
\end{abstract}

\section{Highlights}

0 Farmers' fairs are playing an effective role in information dissemination, but must be updated each year to catch more attention of the farmers.

(0 Infrastructural constraints were perceived highest by the farmers in adoption of transfer of technologies during farmers' fair with composite index value (CIV) of 38.28, followed by physical, institutional, miscellaneous and social constraints.

Keywords: Agriculture, constraints, farmer fair and remedies suggested

Kisan Melas/famers' fair are in subsistence for a long time and regarded as one of the most effective technology dissemination tool. Despite various ICT tools are available for information dissemination, farmers' fair continued to be a significant mode of transfer of technology owning to many advantages (Gangil et al.
2019). The main purpose of organizing such farmers' fair is to create awareness among visitors about new

How to cite this article: Sattari, A.A., Malik, A.K., Yadav, K., Kumar, R. and Kumar, D. (2021). Perception of the Farmers regarding Constraints Faced during Farmers' Fair. Int. J. Soc. Sci., 10(01): 45-50.

Source of Support: None; Conflict of Interest: None 
technologies developed by researchers primarily from the government sector, agricultural and allied research centres and State Agricultural Universities (SAUs) (Pratap et al. 2019).

Extension is one of the three major mandates of the CCS Haryana Agricultural University, Hisar. The responsibility for planning, organizing, conducting and coordinating the extension education activities of the university in Haryana lies with the Directorate of Extension Education. Farmers' fair is one of the most importantextensioneducationactivities of the Directorate for transfer of technology to the potential users/farmers. The farmers' fairs are organized in the both crop seasons for two days during rabi and kharif seasons. Thousands of farmers from Haryana and adjoining states i.e. Uttar Pradesh, Rajasthan, Himachal Pradesh, Uttarakhand, and union territory of Delhi visit the fair. In 1982, the fair attracted only 10,000 farmers, whereas the farmers' fairs organized in 2019 attracted about 75,000 farmers indicating the utility and popularity of the activity (hau. ac.in). There are two types of farmers' fairs organized by the university every year i.e. State level farmers' fair and regional level farmers' fair. State level farmers' fair is popularly known as 'Kisan Mela' is organized on campus in the months of March and September. On this occasion, an agro-industrial exhibition is also organized consisting stalls of government, semi-government and private organizations dealing with agriculture and allied fields to display their products viz., hybrid seeds, fertilizers, tractors, mineral mixture, medicine, different utensils used in dairying, etc. to make the visiting farmers aware of the utility of these products. Moreover, scientists also give information about quality seed, good agriculture practices model, use of chemical fertilizer, information about soil health, animal diseases, identification of quality dairy animal, different livestock products technology, discuss problems related to animal reproduction, management of different livestock, different pathological condition of animal and use of organic manures (Yadav and Kumar, 2018). Information is also provided on insect/pest and disease control management of crops. However, organizing of such farmer fairs demand a lot of investments and time. Authorities, scientists, other staff and development professionals need to spend several weeks to organize such events (Tanush and Chander, 2019). But the visitors of the farmers' fair always perceived some constraints during their visit to fair.

Keeping in view the above facts and importance of agricultural technology for the country in general and farming community of Haryana state in particular, the study was carried out to identify the constraints perceived by the farmers and remedies suggested for improvement of farmers' fair.

\section{MATERIALS AND METHODS}

The study was conducted in 2019-20 during the farmers' fair (rabi) organized by Directorate of Extension Education, CCS Haryana Agricultural University, Hisar at university campus. The farmers visiting the farmers' fair (rabi) were taken as the sample. After completion of their visit, 40 farmers were selected through simple random sampling technique each day for successive two days of the fair. In this way, a total number of 80 farmers were selected for the study during the farmers fair. The data were collected through personal interview technique with the help of well-structured and pretested interview schedule and analyzed using $26^{\text {th }}$ version of the Statistical Package for Social Sciences (SPSS) for computing frequency, percentage, mean and standard deviation.

Constraints were studied under various components viz., technical, physical, social, infrastructural and miscellaneous. These were analyzed using the composite index method followed by Aiswarya (2016) with slight modifications. The responses of fair visiting farmers' were obtained on three-point continuum as very serious, serious and not so serious and scores were given as 2, 1 and 0 , respectively and weighted mean score, index value and rank order were assigned accordingly. The following formula was used for calculating the index of each statement and composite index for all the classified constraints:

Index of each statement $=$

$$
\frac{\text { Total score of each statement }}{\text { Maximum score of the statement }} \times 100
$$


Composite index $=\frac{\Sigma x}{M x N x S} \times 100$

Where,

$\Sigma x=$ sum of total scores of all statements (Sum of frequencies multiplied by weight)

$M=$ Maximum score

$N=$ Number of farmers

$S=$ Number of statements

\section{RESULTS AND DISCUSSION}

\section{Perceived constraints by farmers in adoption of transfer of technologies during farmers' fair}

Several constraints had been faced by the farmers in adoption of transfer of technologies during farmers' fair. For the study, in order to study various types of constraints, items were collected under each category.

Examination of data presented in Table 1 indicated that 'lack of interaction with scientists/experts' was very serious constraint faced by the respondents ranked as I with highest index value (IV) of 38.75 followed by 'non-availability of knowledge regarding loans', 'desired variety of seed not available', 'non-repetition demonstration' and 'lack of mushroom cultivation' ranked II, III, IV and V with IV 26.25, 22.50, 17.50 and 15.00 , respectively. It reflected that large number of the respondents expressed 'lack of interaction with scientist/experts' as serious constraint faced by them, which need to be given priority in future. Therefore, it is recommended that organizers should take effective steps so that farmers can have active interaction with the scientists without any hesitation. Study got strength from the study of Bhawana (2002) who also reported that lack of interaction with scientists/experts was the major technical constraint faced by the respondents visiting farmers' fair. Contrary to this, Gangil et al. (2019) reported that non availability of desired quality of seeds, expenses of money, routine work of agriculture is disturbed, and lack of food arrangement and family obligation were the serious constraints faced by the farmers during Kisan Mela.
Under physical constraints the results showed that 'lack of drinking water' ranked as I constraint with highest index value (IV) of 54.37 followed by 'non-availability of rest room', 'lack of staying arrangement', 'lot of dust', 'extreme hot weather' and 'lack of food facility' ranked as II, III, IV, V and VI with IV 25.62, 24.37, 21.25, 20.00 and 19.37, respectively. However, arrangement of drinking water was sufficient but the visitors might be confused about the place of the water arrangement which need to be improved in coming farmers' fair. The results of the study conducted by Bhawana (2002) also concluded that lack of drinking water was the major physical constraint faced by the farmers visiting farmers' fair. Contrary to this, Pratap et al. (2019) reported that lack of food arrangement was the serious constraint faced by the farmers during Kisan Mela.

It was found that, among the social constraints by farmers, 'misbehavior by other farmers' ranked as I constraint with highest index value (IV) of 08.75 followed by 'unpleasant behavior by stall owners' and 'unpleasant behavior of scientists' ranked as II and III with IV 6.25 and 03.75, respectively. It showed that negligible percentage of respondents faced social constraints on account of unpleasant behavior by fellow farmer, scientists and stall owners. This finding derives support from the findings of Bhawana (2002) who reported that misbehavior by other farmers was the major social constraint faced by the respondents.

Under infrastructural constraints, 'transportation facility' ranked as I constraint with highest index value (IV) of 51.87 followed by 'time duration of farmers' fair', 'enquiry centre does not guide properly' and 'very congested' ranked as II, III and IV with IV 26.25, 25.62 and 18.75, respectively. Hence, transportation facility should be provided by the university to the farmers from the bus stand and railway station to the place of farmer fair (Pratap et al., 2019). The findings are in the line with those of Pattnaik et al. (2012) revealed that most of the participants feel that even if they are interested to visit the Krishi Mela, but the lack of transportation facility was one of the major constraints which hinder their visit. Contrary to this, Bhawana (2002) reported that time duration of farmers fair was the major constraint faced by the farmers visiting farmers' fair. 
$\underset{\text { AESSRA }}{\mathbb{N}_{\mathrm{N}}}$ Sattari et al.

Table 1: Ranking of items under different constraints faced in adoption of transfer of technologies during farmers' fair $(n=80)$

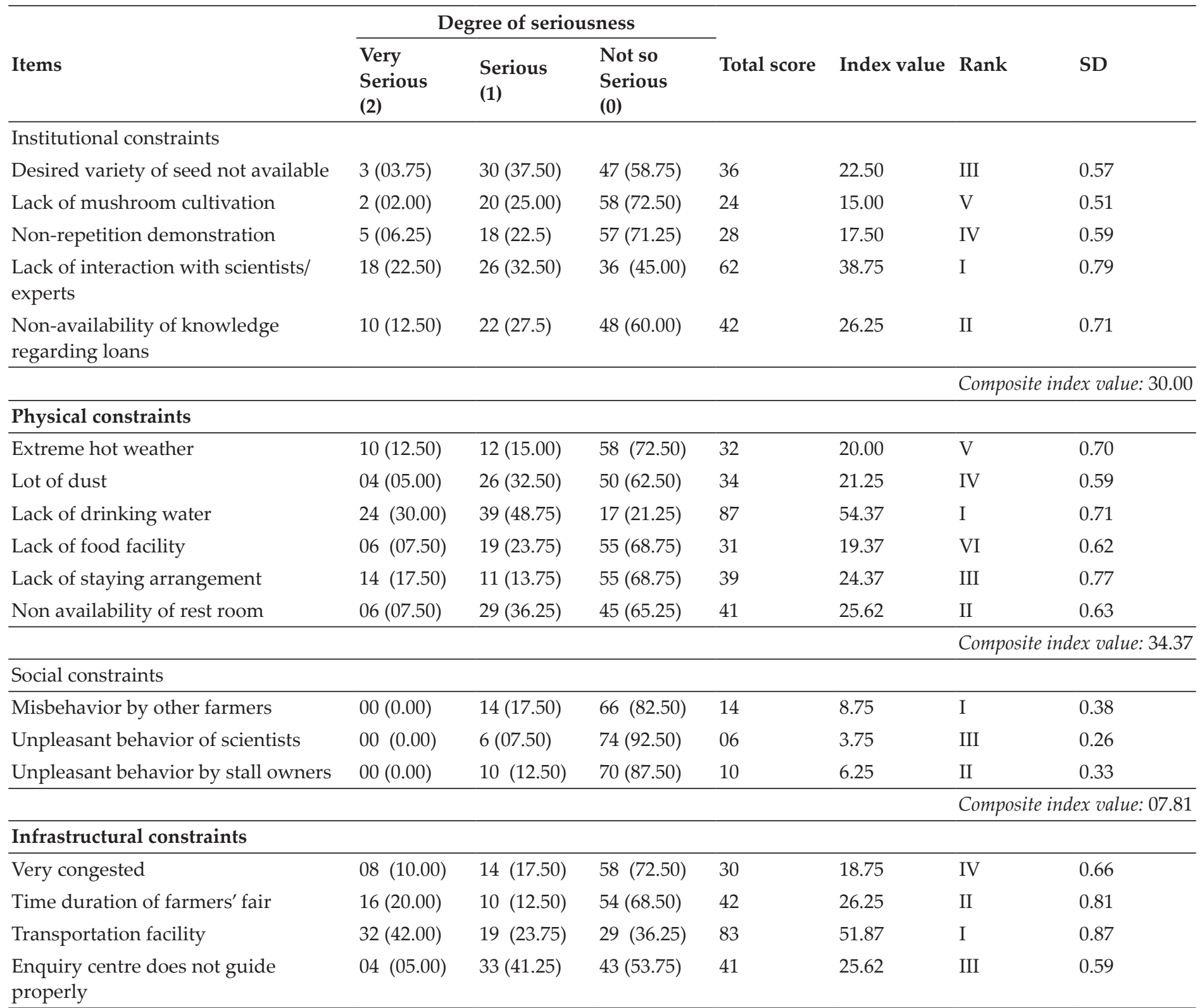

Miscellaneous constraints

\begin{tabular}{|c|c|c|c|c|c|c|c|}
\hline $\begin{array}{l}\text { Require lot of time for visiting farmers' } \\
\text { fair }\end{array}$ & $00(00.00)$ & $18(22.50)$ & $62(77.50)$ & 18 & 11.25 & II & 0.42 \\
\hline Lack of purchasing power & $02(02.50)$ & $8(10.00)$ & $70(87.50)$ & 12 & 07.50 & III & 0.43 \\
\hline
\end{tabular}

Composite index value: 19.27

Note: Figures in parentheses indicate percentage, $S D=$ Standard deviation. 
Perception of the Farmers Regarding Constraints Faced during Farmers' Fair

With regard to miscellaneous constraints, 'lack of money for attending farmers' fair' ranked as I constraint with a highest index value of 27.50 followed by 'require lot of time for visiting farmers' and 'lack of purchasing power' ranked II and III with IV 11.25 and 07.50, respectively. It reflected that most of the farmers perceived that visit to farmers fair is expensive one in terms of money and also a time consuming activity. The probable reason behind this trend might be due to the high transportation cost and person performed number of task at a time. Thus, this constraint might be removed by providing all the necessary equipments and inputs required at the farmers doorstep developed by the different research institutes. Moreover, the growing use of communication methods such as social media and other ICT tools in the current era of digital media has opened the doors to avail any information at just one click instead of travelling to these events (Tanush and Chander, 2019). These results are in conformity with the findings of Swamy et al. (1992) and Manjula et al. (2002). Contrary to this, Talwar (2017) reported that majority of the farmers faced constraints regarding the issue of the chits for seed.

It is observed that among all the constraints faced by the farmers, infrastructural constraints were perceived highest (ranked I) with composite index value (CIV) of 38.28 , followed by physical, institutional, miscellaneous and social constraints ranked II, III, IV and V with CIV $34.37,30.00,19.27$ and 07.81, respectively. Hence, state government and university should also invest more on improving the infrastructural facilities to address the fair related problems of the farmers.

\section{Remedies suggested by farmers for improvement of farmers' fair}

Table 2 indicates that most of the farmers suggested that 'time duration of farmers' fair should be increased' ranked I with a highest index value (IV) 53.12, followed by 'adequate transport facilities', 'seeds should be made available at low price', 'staying arrangement should be improved', 'more emphasis on conservation agriculture training programme' and facility of food and drinking water' ranked II, III, IV, V and IV with IV 52.50, 45.00, $43.75,40.00$ and 36.25 , respectively. The probable reason to suggest remedies for improvement of farmers' fair may be associated due to the fact that these fairs provides latest agricultural information, guides/motivates farmers to adopt new scientific and profitable practices. The findings were partially supported by reports of Kumar et al. (2017) who indicated that latest HYV seed should be available' in Melas, followed by better planning of 'buzz session should be planned and more duration', 'cultural programs on both the days', 'transport facility should be provided from bus stand and railway station', 'staying arrangement should be improved' and 'better facility of food'. Similarly, Bhawana (2002) reported that one-third of the farmers $(38.00 \%)$ were satisfied with farmers' fair and gave no suggestion. While, 16.00 per cent of the farmers suggested regarding new varieties of seed should be made available at low price followed by

Table 2: Ranking of items under remedies suggested for improvement of farmers' fair $(n=80)$

\begin{tabular}{|c|c|c|c|c|c|c|c|}
\hline \multirow[b]{2}{*}{ Items } & \multicolumn{3}{|c|}{ Degree of Seriousness } & \multirow[b]{2}{*}{ Total score } & \multirow[b]{2}{*}{ Index value } & \multirow[b]{2}{*}{ Rank } & \multirow[b]{2}{*}{ SD } \\
\hline & $\begin{array}{l}\text { Very Serious } \\
(2)\end{array}$ & $\begin{array}{l}\text { Serious } \\
(1)\end{array}$ & $\begin{array}{l}\text { Not so Serious } \\
(0)\end{array}$ & & & & \\
\hline $\begin{array}{l}\text { Time duration of farmers' fair should be } \\
\text { increased }\end{array}$ & $33(41.25)$ & $19(23.75)$ & $28(35.00)$ & 85 & 53.12 & I & 0.88 \\
\hline Adequate transport facilities & $32(40.00)$ & $20(25.00)$ & $28(35.00)$ & 84 & 52.50 & II & 0.87 \\
\hline Seeds should be made available at low price & $28(35.00)$ & $16(20.00)$ & $36(45.00)$ & 72 & 45.00 & III & 0.89 \\
\hline Staying arrangement should be improved & $29(36.25)$ & $12(15.00)$ & $39(48.75)$ & 70 & 43.75 & IV & 0.91 \\
\hline \multirow[t]{2}{*}{ More emphasis on conservation agriculture } & $23(28.75)$ & $18(22.50)$ & $47(58.75)$ & 64 & 40.00 & $\mathrm{~V}$ & 0.86 \\
\hline & & & & & \multicolumn{3}{|c|}{ Composite index value: 56.3} \\
\hline
\end{tabular}

Note: Figures in parentheses indicate percentage, $S D=$ Standard deviation 
duration of farmers' fair, availability of transport facility, emphasis on dry land agriculture, improvement in stay arrangement and facility of food and drinking water.

\section{CONCLUSION}

The results of the study revealed that lack of interaction with scientists/experts, lack of drinking water, misbehavior by other farmers, transportation facility and lack of money for attending farmers' fair were the major constraints faced by the respondents in adoption of transfer of technologies under five different categories i.e. institutional, physical, social, infrastructural and miscellaneous. Although these constraints encountered by the farmers could be overcome by implementing remedies suggested by farmers like; time duration of farmers' fair should be increased followed by adequate transport facilities, seeds should be made available at low price, etc., but state government and university should also invest more on improving the infrastructural facilities to address the fair related problems of the farmers. Effective steps must be taken to improve active participation of the farmers so that they can have active interaction with the scientists without any hesitation. Most of the farmers have a lot of queries and problems, so there is an urgent need of Farmer Care Centre that will timely provide them the desired information. Facilities for the visitors such as boarding/ lodging and other civic amenities are the most neglected segment of the fair. So, these arrangements should be addressed properly. Moreover, funding agencies also be encouraged to provide knowledge on loan facilities during the farmers' fair.

\section{ACKNOWLEDGEMENTS}

Authors wish to acknowledge the Chaudhary Charan Singh Haryana Agricultural University, Hisar and all the farmers who participated in the study and made the study successful.

\section{REFERENCES}

Aiswarya, S. 2016. Emotional intelligence among the employees of ESAF microfinance and investment (P) Ltd., MBA (ABM) Unpublished thesis, Kerala Agricultural University, Thrissur.

Bhawana, 2002. Effectiveness of Farmers Fair in Transfer of Technology. Unpublished M.Sc. Thesis. CCSHAU, Hisar, Haryana, pp. 171.

Gangil, D., Singh, A., Verma, H.K. and Kansal S.K. 2019. Perception of the farmers regarding utility of Kisan Mela. Indian J. Extn. Edu., 55(1): 172-175.

Kumar, A., Yadav, K., Kumar, R. and Chander, S. 2017. Perception, perceived utility and implications suggested by farmers on Krishi Melas. Int. J. Edu. and Mgt. Stu, 7(2): 239-240.

Manjula, N., Gowda, G.V., Shashikumar, S. and Kumari Roopa G. 2002. Percept on of farm women about Krishi Mela held at University of Agriculture Sciences, Bangalore. Land Bank J., 20(3): 13-19.

Pattnaik, I., Shah, T., Koppa, G.G. and Shah, A. 2012. Agricultural Extension Service through Krishi Mahotsav in Gujarat: A Preliminary Assessment. GIDR Occasional Paper Series No. 2 Gujarat Institute of Development Research Ahmadabad.

Pratap, J., Khan, M.A., Mandil, R., Singh, V. and Singh, V.P. 2019. Level of satisfaction among farmers attending Kisan Mela. Int. J. Curr. Microbiol. App. Sci., 8(11): 227-234.

Swamy, S.B., Jahagirdar, K.A. and Sontakki, B.S. 1992. Characteristics of participants of Krishimela, Maharastra J. Extn. Edu., 11: 319-323.

Talwar A. 2017. Reactions of the farmers regarding Kisan Mela organized at Punjab Agricultural University, Ludhiana. Unpublished MSc thesis, Punjab Agriculture University, Ludhiana, Punjab.

Tanusha, K. and Chander M. 2019. Constraints Faced by the Tribal Youth in Participation of farmers' fair. Plant Archives, 161: 233-236.

Yadav, K. and Kumar, R. 2018. Farmers Fair in Transfer of Technology: An Effective Extension Approach. Res. J. of Agril. Sci., 9: 53-55. 